\section{Transdiaphragmatic-pericardial Hernia: Case Report of an Unusual Condition Managed by Utilization of a Robotic Surgical System}

\author{
Anupam K. Gupta ${ }^{1}$, Mridul Pansari ${ }^{1}$, Slee Yi ${ }^{2}$, Thomas Genuit ${ }^{1}$, Ariel Rodriguez ${ }^{1}$ \\ 1. Surgery, Charles E. Schmidt College of Medicine, Florida Atlantic University, Boca Raton, USA 2. Surgery, Florida \\ Atlantic University, Boca Raton, USA
}

Corresponding author: Anupam K. Gupta, dranupamkumargupta@gmail.com
Received 01/01/2020

Review began 01/05/2020 Review ended 04/10/2020 Published 04/16/2020

(c) Copyright 2020

Gupta et al. This is an open access article distributed under the terms of the Creative Commons Attribution License CC-BY 4.0., which permits unrestricted use, distribution, and reproduction in any medium, provided the original author and source are credited.
Categories: Cardiac/Thoracic/Vascular Surgery, Miscellaneous, General Surgery

Keywords: diaphragmatic hernia, transdiaphragmatic hernia, iatrogenic hernia, robotic hernia

\section{Introduction}

Atrial fibrillation is one of the most common arrhythmias. A variety of cardiac procedures are used to treat atrial fibrillation. Some of these procedures require a subxiphoid transdiaphragmatic approach $[1,2]$. In this process, the pericardium needs to be opened to approach the heart. Following this approach, the pericardium is typically not closed after and can lead to a potential defect [1-3]. This defect can lead to a rare complication called transdiaphragmatic-pericardial hernia (TDPH).

Diaphragmatic hernias can be acquired or congenital [4,5]. Acquired TDPH is unusual and usually secondary to a prior iatrogenic procedure [4-9].

We would like to present an unusual case of bowel strangulation in a TDPH which occurred secondary to a prior transdiaphragmatic cardiac procedure for atrial fibrillation.

\section{Case Presentation}

A 62-year-old male patient presented to the emergency room with an acute complaint of chest pain. The patient's past medical and surgical history were significant for hypertension, hyperlipidemia, and coronary artery disease. The patient had undergone percutaneous cardiac stent placement and a cardiac ablation procedure for atrial fibrillation, through a subxiphoid transdiaphragmatic approach, 12 years prior.

On presentation, the patient complained of acute-onset substernal chest pain, with radiation to the left arm, associated with one episode of non-projectile bilious vomiting, leading to the evaluation and exclusion of acute cardiac ischemia. The patient's vital signs were within normal limits. On physical examination, the patient's chest examination was within normal limits, and the abdomen was soft, not distended, and without evidence of peritoneal signs. His initial workup included an electrocardiogram and cardiac enzymes, which did not reveal any evidence of myocardial infarction. Laboratory evaluation, including a comprehensive metabolic panel and complete blood count, also demonstrated values within normal limits. CT of the chest and abdomen with and without intravenous contrast revealed the presence of a transdiaphragmatic hernia with apparent small bowel contents adjacent to the heart and within the pericardium (Figure 1). 


\section{Cureus}

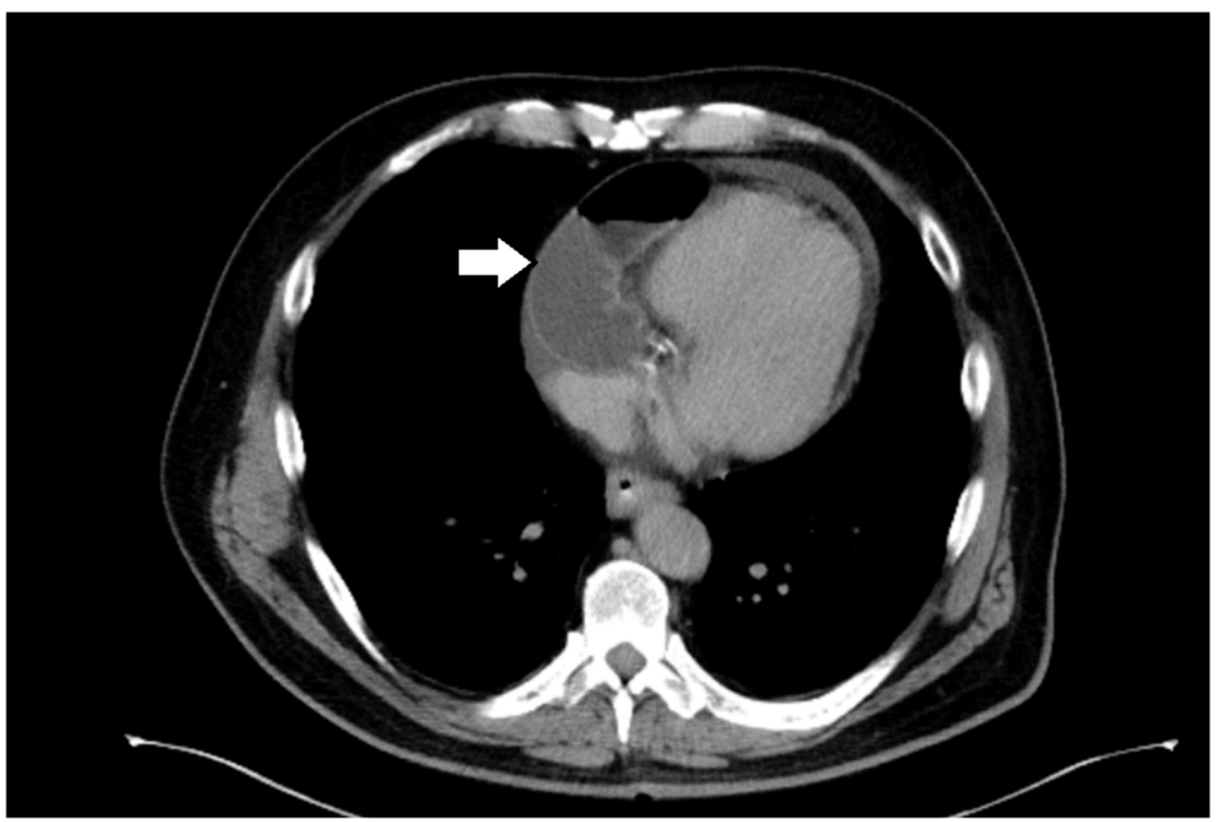

FIGURE 1: Computed tomography demonstrating a small bowel loop next to the heart in the pericardial sac

Given the patient's symptoms, and concerns for possible bowel incarceration, the patient was taken emergently for robotic-assisted surgery (Intuitive da Vinci XI® robotic system, Intuitive Surgical, Sunnyvale, $\mathrm{CA})$. Four 8 -mm ports were placed, two in the right upper quadrant (anterior axillary line), one port in the left upper quadrant (anterior axillary), and one video port in the supraumbilical region. Upon exploration, a loop of small bowel could be seen entering the chest via an anterior midline diaphragmatic defect, which measured approximately $6 \times 4 \mathrm{~cm}$ (Figure 2).

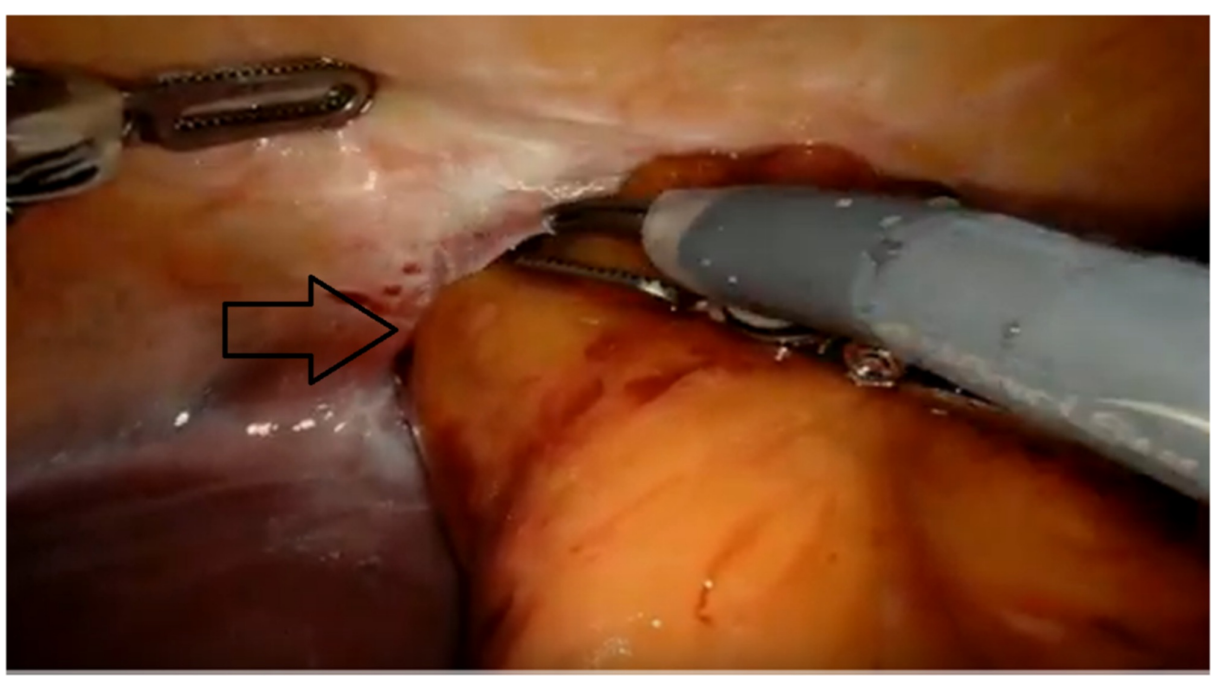

FIGURE 2: Intraoperative view showing the transdiaphragmatic hernia defect with contents entering the pericardial space

Attempts at reducing the herniated bowel were initially unsuccessful due to adhesions and the apparent incarceration of the small bowel loop. After extending the defect laterally in either direction, reduction of the herniated bowel became possible. On inspection, the loop was consistent with the proximal jejunum and demonstrated a 5 -cm segment of transmural ischemia. The ischemic segment was resected, and the bowel continuity restored with a stapled side-to-side, functional end-to-end jejunojejunostomy. The pericardium was inspected and carefully irrigated; there was no evidence of intrapericardial inflammation or infection. The pericardial defect was closed primarily using a continuous 2.0 polydioxanone (PDS) suture and the diaphragmatic defect was then closed, using a poly-4-hydroxybutyrate (P4HB) surgical mesh with a hydrogel barrier (Phasix-ST®, C.R. Bard, Inc., Murray Hill, NJ). The mesh was secured to the diaphragm 
circumferentially with interrupted 2.0 polyglactin (Vicryl) sutures.

Postoperatively, the patient's recovery was uneventful; he was started on a liquid diet on day 1 and advanced to a regular diet by day 3 . The patient was discharged on postoperative day 3 and at the two-week follow up visit, the patient was doing well without any signs of complications.

\section{Discussion}

TDPH is a rare condition. It can occur due to diaphragmatic-pericardial defects that are usually the sequelae of traumatic injuries or the iatrogenic creation of a defect [3-6]. Iatrogenic defects most often follow coronary bypass surgery, particularly when using a right gastroepiploic artery graft, following subxiphoid procedures, including pericardial window or procedures for atrial fibrillation or after esophagectomy [13]. The herniation of abdominal contents is a result of pressure differences between the abdomen and thoracic cavity and may involve any of the abdominal hollow viscus organs [7-9]

The clinical presentation of TDPH may be variable. Patients can present with symptoms of chest pain, mimicking cardiac ischemia or abdominal pain, indigestion and nausea with or without vomiting, or can be asymptomatic. This makes the clinical diagnosis at times difficult [4-9]. The physical examination is often not helpful but can include the findings of bowel sounds over the mid-chest, decreased breath sounds over the left anterior lung fields, and the absence of a cardiac apex impulse [6-11]. Imaging is key in the diagnosis of TDPH: plain-film chest radiography may demonstrate an enlarged cardiac silhouette and/or what appears to be a pneumopericardium, but is often not diagnostic [8]. CT of the chest and abdomen reveals the herniated viscera within the pericardium [4].

Once the diagnosis is made, urgent or emergent surgical repair is indicated to prevent secondary complications of bowel incarceration, strangulation, or the physiologic effects of cardiac tamponade. Both open and laparoscopic surgical repairs have been reported for TDPH, using both abdominal and thoracic approaches $[4-9,12]$. When utilizing a thoracic approach, individual case reports have described using a median sternotomy, but most successfully utilized a left anterior lateral thoracotomy or minimally invasive approach, avoiding the added morbidity associated with median sternotomy $[4,5,8]$.

Primary repair of the diaphragmatic defect with non-absorbable or slowly absorbable monofilament suture may be feasible for smaller defects; a mesh repair is most often used for larger defects. Most surgeons seem to use composite mesh; however, there is no clear consensus on the type of mesh most appropriate for diaphragmatic hernia repair [3-13]. Robotic-assisted surgical approaches are becoming increasingly popular, as they can provide added ability for visualization and dexterity while mobilizing the herniated contents and repairing the TDPH defect [14].

In the published literature, pericardial defects after cardiac interventions are most often left unclosed [1,2]. While thousands of these procedures are performed annually all over the world, the true incidence of TDPH is unknown $[9,10,13]$.

\section{Conclusions}

TDPH is a rare diagnosis that requires urgent or emergent surgical therapy. A minimally invasive use of robotic-assisted surgery may permit better visualization, manipulation of hernia contents, and easier repair of the defect.

\section{Additional Information \\ Disclosures}

Human subjects: Consent was obtained by all participants in this study. Conflicts of interest: In compliance with the ICMJE uniform disclosure form, all authors declare the following: Payment/services info: All authors have declared that no financial support was received from any organization for the submitted work. Financial relationships: All authors have declared that they have no financial relationships at present or within the previous three years with any organizations that might have an interest in the submitted work. Other relationships: All authors have declared that there are no other relationships or activities that could appear to have influenced the submitted work.

\section{References}

1. Badhwar N, Al-dosari G, Dukes J, Lee RJ: Subxiphoid hybrid approach for epicardial/endocardial ablation and LAA exclusion in patients with persistent and longstanding atrial fibrillation. J Atr Fibrillation. 2018, $11: 2014$.

2. Zembala MO, Suwalski P: Minimally invasive surgery for atrial fibrillation. J Thorac Dis. 2013, 5:704-712. 10.3978/j.issn.2072-1439.2013.10.17

3. Takiuchi H, Totsugawa T, Tamaki T, Kuinose M, Yoshitaka H, Tsusima Y: Intrapericardial diaphragmatic hernia after coronary artery bypass grafting using the right gastroepiploic artery graft: report of a case. Ann Thorac Cardiovasc Surg. 2011, 17:624-627. 10.5761/atcs.cr.11.01666 


\section{Cureus}

4. Pathak D, Tantia O, Chaudhuri T, Singh JP: A rare variant of diaphragmatic hernia through the central tendon: a case report. Indian J Surg. 2014, 76:234-236. 10.1007/s12262-013-0959-4

5. Heiner JD, Harper HM, Mcarthur TJ: Intrapericardial diaphragmatic hernia . West J Emerg Med. 2010, 11:532533.

6. Sutton JP, Carlisle RB, Stephenson SE: Traumatic diaphragmatic hernia. A review of 25 cases . Ann Thorac Surg. 1967, 3:136-150. 10.1016/s0003-4975(10)66703-3

7. Meng RL, Straus A, Milloy F, Kittle CF, Langston H: Intrapericardial diaphragmatic hernia in adults . Ann Surg. 1979, 189:359-366. 10.1097/00000658-197903000-00018

8. Iochum S, Ludig T, Walter F, Sebbag H, Grosdidier G, Blum AG: Imaging of diaphragmatic injury: a diagnostic challenge?. Radiographics. 2002, 22:S103-S118. 10.1148/radiographics.22.suppl 1.g02oc14s103

9. Swartz D, Livingston C, Tio F, Mack J, Trinkle JK, Grover FL: Intrapericardial diaphragmatic hernia after subxiphoid epicardial pacemaker insertion: case reports. J Thorac Cardiovasc Surg. 1984, 88:633-635. 10.1186/s40792-018-0499-z

10. Kovacich JC, Boyle EM Jr, Needle D, Maier RV: Iatrogenic intrapericardial diaphragmatic hernia associated with cardiac tamponade. J Trauma. 2001, 50:136-139. 10.1097/00005373-200101000-00028

11. Spiliotopoulos K, de la Cruz KI, Gkotsis G, Preventza O, Coselli JS: Repair of intrapericardial diaphragmatic hernia during aortic surgery in a 78-year-old woman. Tex Heart Inst J. 2017, 44:150-152. 10.14503/THIJ-165985

12. Tyagi S, Steele J, Patton B, Fukuhara S, Cooperman A, Wayne M: Laparoscopic repair of an intrapericardial diaphragmatic hernia. Ann Thorac Surg. 2014, 97:332-333.

13. Gasior AC, St. Peter SD: A review of patch options in the repair of congenital diaphragm defects . Pediatr Surg Int. 2012, 28:327-333.

14. Seetharamaiah R, Romero RJ, Kosanovic R, et al.: Robotic repair of giant paraesophageal hernias. JSLS 2013, 17:570-577. 10.4293/108680813X13654754534594 